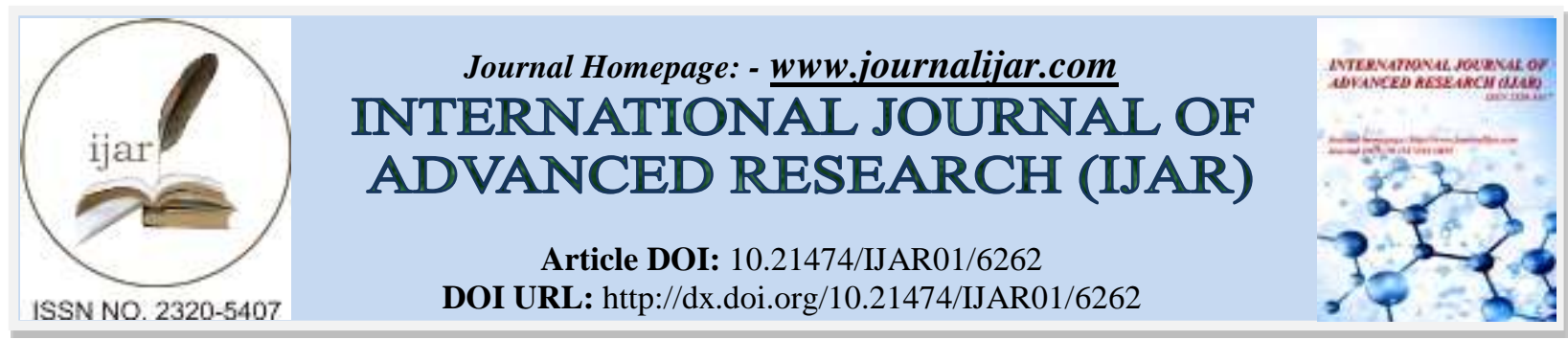

RESEARCH ARTICLE

\title{
SCREENING OF CUSHING'S SYNDROME IN PATIENTS WITH POORLY CONTROLLED TYPE 2 DIABETES WITH HYPERTENSION AND OBESITY.
}

\author{
Karuppiah $\mathrm{D}^{1}$, Cooray MSA ${ }^{1}$, Somasundaram $\mathbf{N}^{1}$ and Ediriweera $\mathrm{DS}^{2}$. \\ 1. Endocrine unit, National Hospital of Sri Lanka. \\ 2. Faculty of Medicine, University of Kelaniya, Sri Lanka.
}

\section{Manuscript Info}

Manuscript History

Received: 09 November 2017

Final Accepted: 11 December 2017

Published: January 2018

Key words:-

Cushing's syndrome, hypertension, obesity, diabetes.

\section{Abstract}

Introduction: Cushing's syndrome (CS) may be unrecognized in patients with diabetes. There is no consensus on routine screening for CS in patients with type 2 diabetes (T2DM). Aim of the study was to evaluate the prevalence of unsuspected CS in out-patients with diabetes.

Methods: Cross sectional prospective study was conducted at diabetes clinic in National Hospital of Sri Lanka among patients with diabetes who were attending for out-patient visit from January-2016 to January2017. Total of 287 patients were investigated with over-nightdexamethasone-suppression test (ODST) as screening test. Patients who fail to suppress serum cortisol less than 50nmol/1 were further tested by Low-dose-dexamethasone-suppression test (LDDST). A third step midnightcortisol measurement was performed in patients who were failed to suppress cortisol less than $50 \mathrm{nmol} / \mathrm{l}$ on LDDST. Fourth step imaging studies with pituitary MRI, abdominal-CT or CT-scan of chest abdomen and pelvis depending on the ACTH levels were performed.

Results: Out of $287,46.18 \%$ (133) patients failed to suppress cortisol to less than $50 \mathrm{nmol} / 1$ on ODST. Among these 133, 23(11.49\% of total) patients failed to suppress cortisol less than $50 \mathrm{nmol} / \mathrm{l}$ on LDDST. Nine out-of 23 patients had cortisol more than 140nmol/1 on midnightcortisol test, confirming true CS. Further investigations with imaging revealed one with pituitary adenoma, one with adrenal adenoma and 6 had normal imaging.

Conclusion: Considering the prevalence of definitive CS of $3.18 \%$ among poorly controlled T2DM patients with hypertension and obesity suggest that CS is not rare as previously thought. But in our Asian population with T2DM and high prevalence of co-morbidities, taking overnight dexamethasone suppression test alone as a screening test would not be suitable test to screen CS.

Copy Right, IJAR, 2018,. All rights reserved.

\section{Introduction:-}

Cushing's syndrome (CS) reflects the biological effects of excessive endogenous or exogenous cortisol secretion. When the hypercortisolism is mild, there will be difficulties in differentiating true CS from Cushing's phenotype and 
metabolic syndrome. Although the prevalence of Cushing's syndrome is very small in general population, it may be more prevalent in certain high risk patient populations with poorly controlled type 2 diabetes (T2DM), hypertension and obesity (Federica Guaraldi. 2012). Some studies show the prevalence of CS among patients with T2DM with poor glycemic control is much higher than in the general population (Gungunes, et al. 2014). Among the different studies there is a wide range from 0 to $9.4 \%$ in the prevalence of CS in patients with T2DM (Krarup, et al. 2012; Bogdan Catargi, et al. 2003). Among hypertensive patients the prevalence of CS is $2.1 \%$ in one study and some evidence suggests high prevalence of CS among simple obesity (Omura, et al. 2004; Sabin SB, et al. 2013).

Studies show patients with incidentally diagnosed adrenal tumors with subclinical hypercortisolism experience clinical and biochemical improvement in diabetes, hypertension and obesity after the removal of adrenal tumor (Reincke, et al., 1992). This confirms that screening for a rare disorder will be more productive if done in a welltargeted high risk cohort. Number of studies have attempted to examine the prevalence of CS in patients with T2DM though no consensus has emerged on value of routine screening for CS in T2DM. Therefore we designed this study to estimate the prevalence of CS in a cohort of overweight type 2 diabetes patients with hypertension and poor glycaemic control.

\section{Subjects and Methodology:-}

This cross sectional prospective study was conducted at diabetes clinic in National Hospital of Sri Lanka among patients with diabetes who were attending for out-patient visit from January 2016 to January 2017. Two hundred and eighty seven consecutive patients who fulfilled following inclusion criteria were included in this study; age above 18 years, poorly controlled type 2 diabetes with $\mathrm{HbAlc}$ of $8 \%$ or more, obesity (BMI of $27 \mathrm{KgM}^{-2}$ or more) and hypertension (blood pressure more than $140 / 80 \mathrm{mmHg}$ ) or on antihypertensive medications. Diagnosed patients with pre-existing CS, patients with severe nephropathy with eGFR $<30 \mathrm{ml} / \mathrm{min} / \mathrm{M}^{2}$ or patients who are on medications which interfere the screening and confirmatory tests were excluded from this study.

Ethical approval and patient consent: The study was approved by the ethical committee of university of Colombo and permission from the director, National Hospital of Sri Lanka was obtained for utilizing the data and conducting the study. Informed written consent was obtained from all patients.

\section{Materials and protocols:-}

The patients in the inclusion criteria were investigated with over-night dexamethasone suppression test (ODST) as screening test for CS. Patients were advised to take $1 \mathrm{mg}$ dexamethasone orally at $2300 \mathrm{~h}$ and blood samples were collected on the following morning at 0800 for determination of plasma cortisol concentration. Patients who fail to suppress serum cortisol less than 50nmol/l were further tested by Low dose dexamethasone suppression test (LDDST). For LDDST patients were advised to take $0.5 \mathrm{mg}$ dexamethasone orally 6 hourly for 48 hours at 0900 , 1500, 2100, 0300 and serum cortisol was measured at time 0 and 48h. A third step midnight cortisol measurement was performed in patients who were failed to suppress cortisol less than 50nmol/l on LDDST as confirmatory test for presence of CS. Midnight serum cortisol was done while the patient was asleep after at least 48 hours hospitalization. A serum cortisol value higher than $140 \mathrm{nmol} / \mathrm{L}$ was characterized CS. When a value was lower than $50 \mathrm{nmol} / 1$, it ruled out the diagnosis. Basal ACTH levels were obtained in patients with elevated midnight cortisol. All hormonal tests was carried out at chemical pathology lab, National Hospital of Sri Lanka by radio immune assay. As a fourth step imaging studies with pituitary MRI, abdominal CT or CT scan of chest abdomen and pelvis depending on the ACTH levels were performed.

\section{Statistical analysis:-}

Results are given as means with standers deviation. The comparison between variables (age, duration of diabetes, BMI, waist to hip ratio, $\mathrm{HbA1c}$, blood pressure, and cortisol) among patients with CS and with-out CS were done using Pearson's Chi-squre test and Fisher's exact test. Continuous variables were tested for normality using Shapiro Wilk test and none of the variables were normally distributed, therefore Wilcoxon sign rank test was used to compare continuous variables in CS and with-out CS groups. The level of statistical significance was considered at $\mathrm{p}<0.05$. The programing language version was 3.2.3.

\section{Results:-}

The study flow chart was shown in figure 1 . Total patients included to the initial screening was 287 . Table 1 illustrates the baseline characteristics of the patients included. Number of patients failed to suppress cortisol to less than 50nmol/l on ODST (positive ODST) was 133 (46.18\%). Further evaluation was done with LDDST for these 
133 ODST positive patients. Twenty three (11.49\% of total) patients failed to suppress cortisol less than 50nmol/l. A third step mid night cortisol measurement was carried out in these 23 LDDST positive patients, which revealed 9 patients with cortisol more than $140 \mathrm{nmol} / \mathrm{l}$ confirming true CS. Among these 9 patients $(3.18 \%$ of total), six had basal ACTH levels more than 10pmol/1, two were in between 5 and $10 \mathrm{pmol} / \mathrm{l}$ and one had low ACTH of 5pmol/1. Further investigations revealed macroadenoma of pituitary gland on MRI in one patient. Subsequent surgery confirmed corticotroph adenoma. One patient with high ACTH declined further investigations. One had normal pituitary but $2 \mathrm{~cm}$ right adrenal adenoma and planning for repeat scan in 6 months. No pituitary or adrenal tumour was found in five patients. One patient with ACTH of 5pmol/1 underwent adrenal CT and not found any lesion. The source of the hypercortisolism was in these 6 patients remain unknown (Table 2). Table 3 shows the comparison of patients with confirmed CS (positive for all 3 screening test) and rest of patients.

\section{Discussion:-}

The prevalence of CS in patients with T2DM is widely varying from 0 to $9.4 \%$ on different studies. This variation is due to number of factors including the study setting, study population and the cut-off values used for screening tests. Studies carried out among in-patients with T2DM showed prevalence of 2 to 9.4\% (Leibowitz, et al. 1996; Catargi, et al. 2003; Chiodini,et al. 2005; Taniguchi,et al. 2008; Murakami, et al. 2010), whereas outpatient set-up showed prevalence of 0 to 2.9\% (Caetano MS, et al. 2007; Newsome, et al. 2008; Gagliard, et al. 2010; Mullan, et al. 2010). Studies used ODST as a screening test showed more prevalence than studies used midnight salivary cortisol (2$9.4 \%$ vs $0-2.9 \%$ ). The number of study population were ranged from 77 to 294 in these studies. Some studies used $140 \mathrm{nmol} / 1$ as the cut off values for ODST and some have taken 50nmol/1. The studies carried out on newly diagnosed patients with diabetes was showed $1 \%$ of the prevalence of CS in one study and even less than $1 \%$ in another study (Reimondo, et al. 2007; Newsome, et al. 2008).

Although number of studies have attempted to examine the prevalence of CS in patients with T2DM, still no consensus has emerged on value of routine screening for CS in T2DM.

Our study set-up was out-patients with poorly controlled T2DM associated with hypertension and obesity; conferring high probability of CS. We observed nearly half of the subjects were non-suppressors for the initial screening test (ODST) indicating higher false positives in this high risk population. Two screening tests were positive in $11.49 \%$. Only $3.18 \%$ (9 patients out of 287) was confirmed to have CS and rest of 14 were suggestive of pseudo Cushing's based on low mid-night cortisol.

The Endocrine society guidelines currently recommends initial use of one test with high diagnostic accuracy: late night salivary cortisol, 24 hour urine free cortisol and over-night or low dose dexamethasone suppression test (Lynnette et al., 2008). Patients with abnormal result are recommended to undergo a second test with either one of the above or serum midnight cortisol or dexamethasone - CRH test. Patients with CS characteristically have loss of circadian rhythm with absence of late night cortisol nadir (Glass, et al., 1984). This forms the basis of measurement of midnight serum or late night salivary cortisol. ELISA and Liquid chromatography - mass spectrometry are the best validated methods used to measure salivary cortisol (Baid. Et al., 2007). Urinary free cortisol has high accuracy, it measures the unbound cortisol and therefore not affected by conditions and medications that alter the binding (Elamin, et al., 2008). These two methods are easily performed and less invasive tests. Non availability of these tests in our country and higher percentage of false positive results in older, diabetic or hypertensive subjects made us to choose other two recommended tests. In the dexamethasone suppression test, a lower cutoff of 50nmol/1 is recommended by the experts to increase the sensitivity greater than $95 \%$. A sleeping midnight cortisol less than 50nmol/1 effectively excludes CS in a population with low clinical index suspicion (24 Pecori Giraldi, et al. 2007).

Our study protocol used testing strategy to minimize number of false positive results also more convenient and less expensive tests. However with this protocol we may have missed a number of patients with subclinical or mild hypercortisolism. Even with confirmed CS, source of the hypercortisolism was not found in the majority of the patients. The earlier reports of mortality in CS was described among individuals with severe hypercortisolism and most deaths were caused by vascular and infectious complications (Plotz, et al., 1952). Successful normalization of cortisol was resulted in reduction of the standard mortality ratio. But there are limited and conflicting data regarding whether specific treatment of patients with mild hypercortisolism is superior to medical treatment of co-morbidities alone (Reincke 2000; Terzolo, et al. 2004; Tsagarakiset al. 2006; Mitchell, et al. 2007). 


\section{Conclusions:-}

In the present study nearly half of the patients exhibit lack of suppression to ODST. Therefore in our population with T2DM and high prevalence of co-morbidities, taking ODST alone as a screening test would not be suitable test to screen CS. We need at least two screening tests and preferably 3 tests to exclude pseudo Cushing's and reduce the number of imaging tests. Biochemical abnormalities of the hypothalamic pituitary adrenal (HPA) axis on 2 screening tests were positive in $11.49 \%$, but only $3.18 \%$ (9 patients) showed higher midnight cortisol. Whether the remaining 14 patients would have progressed towards overt CS is doubtful. The prevalence of CS among patients with T2DM is comparable to other studies, though it would be even higher if we took only 2 positive tests. Definitive diagnosis with pathological results and origin of the lesion was only found in one patient whereas 6 patients only showed biochemical evidence of CS. This could be occult CS with negative imaging or functional activation of HPA axis observed in obesity and diabetes.

Considering the prevalence of definitive CS of 3.18\% among poorly controlled T2DM patients with hypertension and obesity suggest that CS is not rare than previously thought. Whether this would justify wide-scale screening is uncertain and even in this targeted population with high probability of CS, determining the cause of CS was challenging.

Declaration of Interest: there is no conflict of interest that could be perceived as prejudicing the impartiality of the research reported.

Funding: This research did not receive any specific grant from any funding agency in the public, commercial or not-for-profit sector. 


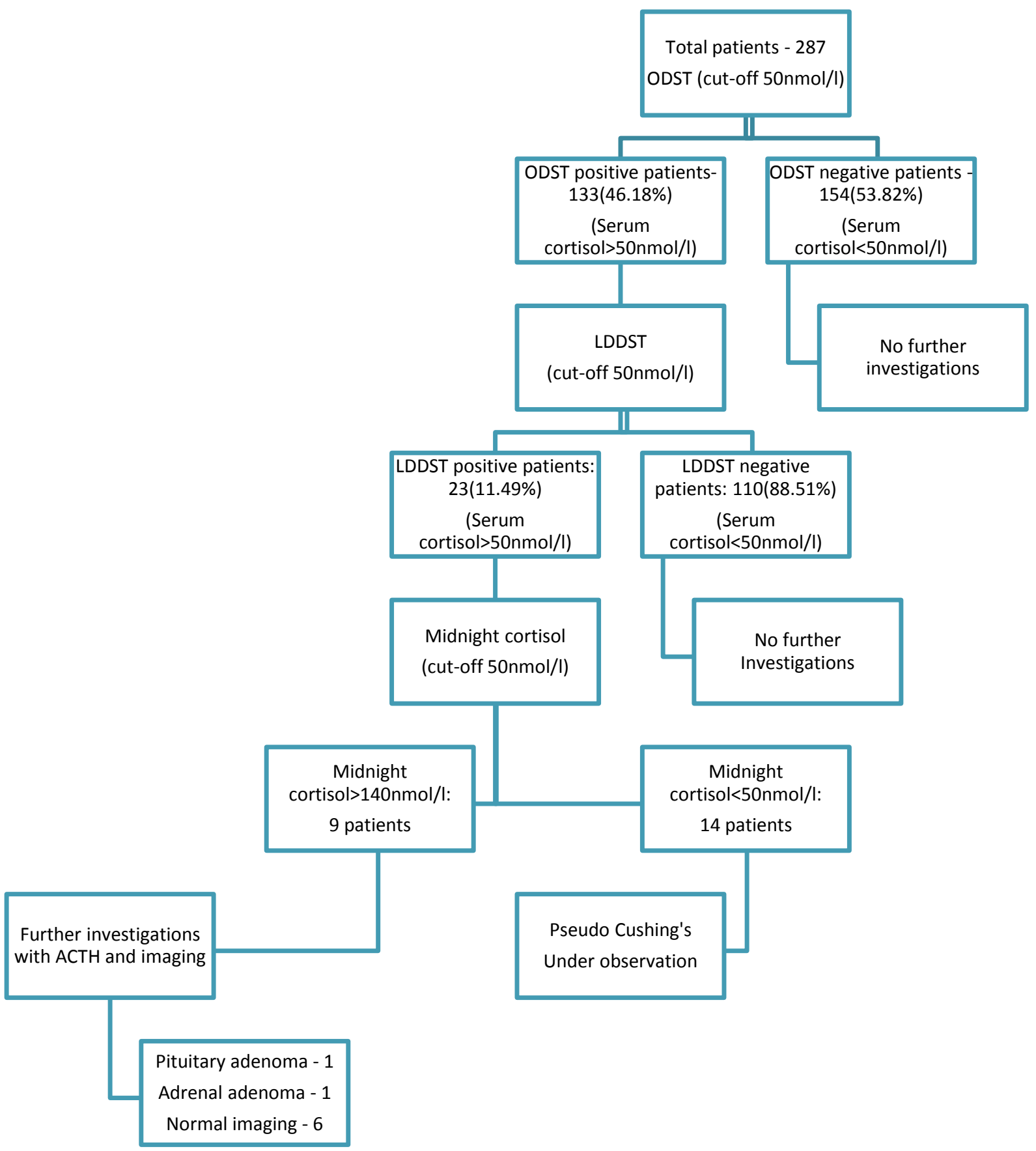

Figure 1:- Flow charts of the study

ODST: over-night dexamethasone suppression test, LDDST: low dose dexamethasone suppression test 
Table 1:- Baseline characteristics of patients included in the study

\begin{tabular}{|l|l|l|}
\hline Variables & Mean & SD \\
\hline Age (years) & 55.7 & 8.5 \\
\hline Duration of Disease (years) & 13.1 & 7.5 \\
\hline BMI $\left(\mathrm{kg} / \mathrm{m}^{2}\right)$ & 31.1 & 3.6 \\
\hline Waist/hip ratio (WHR) & 0.99 & 1.8 \\
\hline Systolic blood pressure (SBP) (mmHg) & 137.4 & 18.6 \\
\hline Fasting blood glucose(FBS) (mg/dl) & 153.8 & 55.4 \\
\hline HbA1C $(\%)$ & 9.9 & 1.5 \\
\hline Total cholesterol $(\mathrm{TC})(\mathrm{mg} / \mathrm{dl})$ & 182 & 40.5 \\
\hline LDL cholesterol $(\mathrm{mg} / \mathrm{dl})$ & 107.7 & 34.9 \\
\hline ALT & 35.0 & 18.1 \\
\hline Total body fat\% & 38.7 & 5.5 \\
\hline
\end{tabular}

Table 2:- Characteristics of patients with confirmed Cushing's syndrome

\begin{tabular}{|l|l|l|l|l|l|l|l|}
\hline Patient & Age (Y) & $\begin{array}{l}\text { ODST } \\
\text { nmol/l }\end{array}$ & $\begin{array}{l}\text { LDDST } \\
\text { nmol/l }\end{array}$ & $\begin{array}{l}\text { Mid- } \\
\text { night } \\
\text { cortisol } \\
\text { nmol/l }\end{array}$ & $\begin{array}{l}\text { ACTH } \\
\text { pmol/1 }\end{array}$ & Imaging & Patient out come \\
\hline 1 & 49 & 68 & 65 & 245 & 255 & $\begin{array}{l}\text { MRI - 2.2x2.5cm pituitary } \\
\text { adenoma }\end{array}$ & $\begin{array}{l}\text { TSA confirmed } \\
\text { corticotroph } \\
\text { adenoma }\end{array}$ \\
\hline 2 & 60 & 55 & 55 & 263 & 30.7 & $\begin{array}{l}\text { Declined further } \\
\text { investigations }\end{array}$ & \\
\hline 3 & 60 & 62 & 50 & 156 & 12.2 & $\begin{array}{l}\text { Normal pituitary MRI and } \\
\text { CT Chest and abdomen }\end{array}$ & \\
\hline 4 & 57 & 55 & 68 & 325 & 8.3 & $\begin{array}{l}\text { Normal pituitary MRI and } \\
\text { CT Chest and abdomen }\end{array}$ & \\
\hline 5 & 59 & 80 & 55 & 345 & 5.1 & CT abdomen - normal & \\
\hline 6 & 50 & 60 & 66 & 246 & 8.6 & $\begin{array}{l}\text { Normal pituitary MRI and } \\
\text { CT Chest and abdomen }\end{array}$ & $\begin{array}{l}\text { CT abdomen - 2cm Right } \\
\text { adrenal mass }\end{array}$ \\
\hline 7 & 63 & 393 & 60 & 168 & 13.7 & $\begin{array}{l}\text { Rormal pituitary MRI and } \\
\text { CT Chest and abdomen }\end{array}$ & \\
\hline 8 & 67 & 75 & 60 & 443 & 18 & $\begin{array}{l}\text { Normal pituitary MRI and } \\
\text { CT Chest and abdomen }\end{array}$ & \\
\hline 9 & 57 & 56 & 61 & 254 & 21 & \\
\hline
\end{tabular}

Table 3:- Comparison of patients with confirmed Cushing's syndrome (positive for all 3 screening test) and rest of patients

\begin{tabular}{|l|l|l|l|}
\hline Variables (median) & $\begin{array}{l}\text { Patients with } \\
\text { confirmed CS (N=9) }\end{array}$ & $\begin{array}{l}\text { Patients with-out } \\
\text { confirmed } \\
\text { CS=278) }\end{array}$ & $\begin{array}{l}\text { P value } \\
\text { (Wilcoxon } \\
\text { test) }\end{array}$ \\
\hline Age (year) & $59(56-61)$ & $56(50-62)$ & 0.40 \\
\hline Duration of T2DM (year) & $16(15-18)$ & $12(8-17)$ & 0.15 \\
\hline BMI (kg/m m $^{2}$ & $30(28-34)$ & $31(28-33.8)$ & 0.98 \\
\hline Waist/hip ratio (WHR) & $0.9(0.9-0.9)$ & $0.9(0.8-0.9)$ & 0.19 \\
\hline Systolic blood pressure (SBP) (mm Hg) & $140(130-140)$ & $135(120-150)$ & 0.73 \\
\hline Fasting blood glucose(FBS) (mg/dl) & $167(135-171)$ & $145(112-184)$ & 0.46 \\
\hline HbAlc & $11(8.4-12.1)$ & $9.6(8.8-10.8)$ & 0.26 \\
\hline Total body fat \% & $41.3(39.2-42.9)$ & $39.4(35.6-42.4)$ & 0.29 \\
\hline
\end{tabular}




\section{References:-}

1. Baid SK, Sinaii N, Wade M, Rubino D, Nieman LK. (2007). Radioimmunoassay and tandem mass spectrometry measurement of bedtime salivary cortisol levels: a comparison of assays to establish hypercortisolism. J Clin Endocrinol Metab. 92:3102-3107

2. Bogdan Catargi, et al. (2003). Occult Cushing's Syndrome in Type 2 diabetes, JCEM, vol 88, issue 12 . Doi http://dx.doi.org/10.1210/jc.2003-030254

3. Caetano MS,Silva R, Kater CE. (2007). Increased diagnostic probability of subclinical Cushing's syndrome in a population sample of overweight adult patients with type 2 diabetes mellitus. Arq Bras Endocrinol Metabol 51:1118-1127.

4. Catargi B, Rigalleau V, Poussin A, Ronci-Chaix N, Bex V, Vergnot V, Gin H, Roger P, Tabarin A. (2003). Occult Cushing's syndrome in type-2 diabetes. J Clin Endocrinol Metab 88:5808-5813

5. Chiodini I, Torlontano M, Scillitani A, Arosio M, Bacci S, Di Lembo S, Epaminonda P, Augello G, Enrini R, Ambrosi B, Adda G, Trischitta V. (2005). Association of subclinical hypercortisolism with type 2 diabetesmellitus:acase-controlstudyinhospitalizedpatients.Eur J Endocrinol 153:837-844.

6. Elamin MB, Murad MH, Mullan R, Erickson D, Harris K, Nadeem S, Ennis R, Erwin PJ, Montori VM. (2008). Accuracy of diagnostic tests for Cushing syndrome: a systematic review and meta-analyses.J Clin Endocrinol Metab 93:1553-1562.

7. Federica Guaraldi. (2012). Cushing Syndrome may not be so uncommon of an endocrine disease, Journal of the American Board of Family Medicine. 25(2):199-208

8. Gagliardi L, Chapman IM, O’Loughlin P, Torpy DJ. (2010). Screening for subclinical Cushing's syndrome in type 2 diabetes mellitus: low false-positive rates with nocturnal salivary cortisol. Horm Metab Res 42:280-284

9. Glass AR, Zavadil AP, Halberg F, Cornelissen G, Schaaf M. (1984). Circadian rhythm of serum cortisol in Cushing's disease. J Clin Endocrinol Metab. 59:161-165.

10. Gungunes A, Sahin M, Demirci T, Ucan B, Cakir E, Arslan MS, Unsal IO, Karbek B, Calıskan M, Ozbek M, Cakal E, Delibasi T. (2014). Cushing's syndrome in type 2 diabetes patients with poor glycemic control. Endocrine.

11. Krarup T, Krarup T, Hagen C. (2012). Do patients with type 2 diabetes mellitus have an increased prevalence of Cushing's syndrome? Diabetes Metab Res Rev. 28(3):219-27. doi: 10.1002/dmrr.2262.

12. Leibowitz G, Tsur A, Chayen SD, Salameh M, Raz I, Cesari E, Gross DJ. (1996). Pre-clinical Cushing's syndrome: an unexpected frequent cause of poor glycaemic control in obese diabetic patients. Clin Endocrinol 44:717-722

13. L Lynnette K. Nieman, Beverly M. K. Biller, James W. Findling, John Newell-Price, Martin Savage, Paul M. Stewart, and Victor M. Montori. (2008). The Diagnosis of Cushing's Syndrome: An Endocrine Society Clinical Practice Guideline J Clin Endocrinol Metab. 93(5): 1526-1540. Published online 2008 Mar 11. doi: $10.1210 /$ jc. $2008-0125$

14. Mitchell IC, Auchus RJ, Juneja K, Chang AY, Holt SA, Snyder WH, 3rd, Nwariaku FE. (2007). Subclinical Cushing's syndrome is not subclinical: improvement after adrenalectomy in 9 patients. Surgery 142:900-905.

15. Mullan K, Black N, Thiraviaraj A, Bell PM, Burgess C, Hunter SJ, McCance DR, Leslie H, Sheridan B, Atkinson AB. (2010). Is there value in routine screening for Cushing's syndrome in patients with diabetes? J Clin Endocrinol Metab 95:2262-2265

16. Murakami H, Nigawara T, Sakihara S, Kageyama K, Yamashita M, Matsuki K, Tanabe J, Matsui J, Tamasawa N, Suda T. (2010). The frequency of type 2 diabetic patients who meet the endocrinological criteria of subclinical Cushing's disease. Endocr J 57:267-272.

17. Newsome S, Chen K, Hoang J, Wilson JD, Potter JM, Hickman PE. (2008). Cushing's syndrome in a clinic population with diabetes. Intern Med J 38:178-182.

18. Omura M, et al. (2004). Prospective study on the prevalence of secondary hypertension among hypertensive patients visiting a general outpatient clinic in Japan. Hypertens Res. 27:193-202.

19. Pecori Giraldi F, Pivonello R, Ambrogio AG, De Martino MC, De Martin M, Scacchi M, Colao A, Toja PM, Lombardi G, Cavagnini F. (2007). The dexamethasone-suppressed corticotropin-releasing hormone stimulation test and the desmopressin test to distinguish Cushing's syndrome from pseudo-Cushing's states. Clin Endocrinol (Oxf) 66:251-257.

20. Plotz CM, Knowlton AI, Ragan C. (1952). The natural history of Cushing's syndrome. Am J Med 13:597614.

21. Reimondo G, Pia A, Allasino B, Tassone F, Bovio S, Borretta G, Angeli A, Terzolo M. (2007). Screening of Cushing's syndrome in adult patients with newly diagnosed diabetes mellitus. Clin Endocrinol 67:225-229 
22. Reincke M. (2000). Subclinical Cushing's syndrome. Endocrinol Metab Clin North Am 29:43-56

23. Reincke M, Nieke J, Krestin GP, Saeger W, Allolio B, Winkelmann W. (1992). Preclinical Cushing's syndrome in adrenal"incidentalomas": comparison withadrenal Cushing's syndrome. J Clin Endocrinol Metab. 75:826-32.

24. Sabin SB, et al. (2013). Routine Screening for Cushing's Syndrome Is Not Required in Patients Presenting with Obesity. ISRN Endocrinol. 11;321063. Doi 10.1155/2013/321063

25. Taniguchi T, Hamasaki A, Okamoto M. (2008). Subclinical hypercortisolism in hospitalized patients with type 2 diabetes mellitus. Endocr J 55:429-432.

26. Terzolo M, Reimondo G, Bovio S, Angeli A. (2004). Subclinical Cushing's syndrome. Pituitary 7:217-223.

27. Tsagarakis S, Vassiliadi D, Thalassinos N. (2006). Endogenous subclinical hypercortisolism: diagnostic uncertainties and clinical implications. J Endocrinol Invest 29:471-482. 